\title{
A novel system for in situ determination of heat tolerance of plants: first results on alpine dwarf shrubs
}

\author{
Othmar Buchner*, Matthias Karadar, Ines Bauer and Gilbert Neuner
}

\begin{abstract}
Background: Heat stress and heat damage to plants gain globally increasing importance for crop production and plant survival in endangered habitats. Therefore the knowledge of heat tolerance of plants is of great interest. As many heat tolerance measurement procedures require detachment of plants and protocols expose samples to various heat temperatures in darkness, the ecological relevance of such results may be doubted. To overcome these constraints we designed a novel field compatible Heat Tolerance Testing System (HTS) that opens the opportunity to induce controlled heat stress on plants in situ under full natural solar irradiation. Subsequently, heat tolerance can be evaluated by a variety of standard viability assays like the electrolyte leakage test, chlorophyll fluorescence measurements and visual assessment methods. Furthermore, recuperation can be studied under natural environmental conditions which is impossible when detached plant material is used. First results obtained on three alpine dwarf - shrubs are presented.

Results: When heat tolerance of Vaccinium gaultherioides Bigelow was tested with the HTTS in situ, the visual assessment of leaves showed $50 \%$ heat injury $\left(L T_{50}\right)$ at $48.3^{\circ} \mathrm{C}$, while on detached leaves where heat exposure took place in small heat chambers this already happened at $45.8^{\circ} \mathrm{C}$. Natural solar irradiation being applied during heat exposure in the HTTS had significantly protective effects: In Loiseleuria procumbens L. (Desv.), if heat exposure (in situ) took place in darkness, leaf heat tolerance was $50.6^{\circ} \mathrm{C}$. In contrast, when heat exposure was conducted under full natural solar irradiation heat tolerance was increased to $53.1^{\circ} \mathrm{C}$. In Rhododendron ferrugineum L. heat tolerance of leaves was $42.5^{\circ} \mathrm{C}$ if the exposure took place ex situ and in darkness, while it was significantly increased to $45.8^{\circ} \mathrm{C}$ when this happened in situ under natural solar irradiation.

Conclusions: The results obtained with the HTTS tested in the field indicate a mitigating effect of natural solar irradiation during heat exposure. Commonly used laboratory based measurement procedures expose samples in darkness and seem to underestimate leaf heat tolerance. Avoidance of detachment by the use of the HTTS allows studying heat tolerance and recuperation processes in the presence of interacting external abiotic, biotic and genetic factors under field conditions. The investigation of combined effects of heat exposure under full solar irradiation, of recuperation and repair processes but also of possible damage amplification into the results with the HTTS appears to be particularly useful as it allows determining heat tolerance of plants with a considerably high ecological significance.
\end{abstract}

Keywords: Chlorophyll fluorescence, Electrolyte leakage, Heat stress, Rhododendron, Loiseleuria, Vaccinium, Viability assessment

\footnotetext{
* Correspondence: Othmar.Buchner@uibk.ac.at

University of Innsbruck, Institute of Botany, Sternwartestrasse 15, 6020,

Innsbruck, Austria
}

\section{Biomed Central}

(c) 2013 Buchner et al.; licensee BioMed Central Ltd. This is an Open Access article distributed under the terms of the Creative Commons Attribution License (http://creativecommons.org/licenses/by/2.0), which permits unrestricted use, distribution, and reproduction in any medium, provided the original work is properly cited. 


\section{Background}

High temperature is an important abiotic stress factor for plants that is not restricted to tropical areas and desert belts but also may play an important role in colder regions and at high altitudes [1]. The main reason for heat as an important stress factor in alpine sites are growth forms like rosettes and cushions that plants may have evolved to favor a decoupling from ambient cold air temperature [2]. This improvement of thermal conditions may in turn cause critical overheating as the heat trapping nature can get fatal in situations with high solar irradiation input, combined to restricted transpiration and calm winds causing situations where the thermal high temperature thresholds can get exceeded.

As high altitudes are not excepted from climate change [3] and high mountain vegetation is particularly vulnerable to it [4] especially prostrate species and plants over bare and quickly desiccating soils like many pioneer plants and their seedlings may be affected by heat stress [5-7]. This particularly, if the projected increase in global mean temperature [8] in fact should come true.

Besides natural vegetation the same applies to crop plants. Food production especially in hot and arid regions due to increased temperature has already become an agricultural problem in many areas of the world [9].

Such forecasts emphasize the urgency and the importance of a comprehensive knowledge about heat tolerance and heat stress responses [10] of plants and their capacity to adapt to an increasingly warmer climate. However, this presupposes the availability of practicable and ecologically relevant methods for the assessment of heat tolerance of plants. As is known, under natural environmental conditions heat tolerance of plants may change significantly within short time spans [11-13]. Therefore, in most cases transportation of plants from a distant natural growing site to a laboratory for conducting the heat tolerance test is not meaningful. Many heat tolerance data have been collected during the last centuries using laboratory based test procedures e.g. [14-19], however, ecologically significant data on heat tolerance of plants obtained in in situ measurements on plants at their specific growing site are widely missing and mechanisms of recuperation and repair appear severely understudied.

The classical method for the determination of heat tolerance is a laboratory based test procedure [20,21]. This procedure normally consists of two consecutive phases: (1) the exposure of the samples to controlled heat stress in darkness and (2) the viability assessment based on visual damage or thermal stress dependent cellular functions like cell membrane stability (electrolyte leakage) or chlorophyll fluorescence parameters (non - invasive) $[22,23]$. Until now only two field - portable instrument systems for the determination of heat tolerance on detached plant parts have been described [24,25]. Although with these instruments long transportation times and possible short - term alterations of heat tolerance can be avoided, they still do not allow studying after - effects and recuperation, as the samples have to be detached similar to laboratory tests. Another disadvantage of the existing field - portable systems is that heat exposure has to be conducted in darkness or under weak irradiation. This does not take into account that particularly at high altitudes midday heat usually coincides with high irradiation levels. This, however, may have significant effects on photosynthetic tissues and their ability to withstand heat stress, an aspect that has been totally neglected in the majority of earlier studies. Until today only a few studies on the determination of heat tolerance have been done, where heat stress was applied in the presence of natural solar irradiation using light transmissible tents or plastic bags e.g. [26,27] with the restriction that either temperature control was very limited or movement of plants into growth chambers [28] was necessary.

To overcome these disadvantages we designed and constructed a field compatible Heat Tolerance Testing System (HTTS) which allows in situ determinations of heat tolerance without the necessity to detach plant parts and with the possibility of conducting controlled heat treatments in the presence of natural solar irradiation (light - mode) and - for comparative studies - also in darkness (dark - mode). Heat treatments can be conducted under water vapor saturated air conditions that eliminate unpredictable transpirational cooling effects and ensure best possible isothermics between air and plant material. It is known [29] that heat exposure within an unsaturated atmosphere can have marked effects on the viability, because if transpirational cooling can take place, leaf temperatures will not reach the desired exposure temperature and therefore heat tolerance obtained under such conditions will possibly deviate substantially from those that are determined at $100 \%$ relative humidity.

The inclusion of recuperation and repair studies in the presence of interacting external abiotic, biotic and genetic factors under natural environmental conditions subsequent to controlled heat stress exposure powerfully enhances the ecological significance of the heat tolerance data determined with the HTTS, as they represent the de facto heat tolerance of a certain species at a certain developmental stage at the natural growing site. This will increase the accuracy of risk assessments related to future survival of spontaneous vegetation and will allow optimizing cultivar testing in breeding programs.

We hypothesize (1) that the presence of natural solar irradiation during short - term heat stress events may principally affect heat tolerance of leaves and (2) that heat tolerance determined on excised leaves (ex situ) may significantly differ from results derived from attached leaves 
at the natural growing site (in situ). Therefore, the aim of this study was to test whether heat stress in darkness or heat stress under full solar irradiation is survived better, and to observe possible influence of detachment on the measured heat tolerance. Additionally, the practical feasibility and the main features of the HTTS (in situ heat exposure at natural solar irradiation within a water saturated atmosphere) should be demonstrated under alpine field conditions on the basis of plant species being especially suitable for this purpose. In the following, preliminary results on selected alpine dwarf shrubs are shown obtained with the HTTS in comparison to those achieved with classical tests.

\section{Results}

\section{Effects of relative air humidity on leaf temperatures}

At high but still sub - lethal temperatures and low to moderate relative humidity ( $R h$ ) inside the exposure chambers leaf transpiration has a significant cooling effect on leaf temperature and the scattering of leaf temperatures (Figure 1). This applies both to the dark - mode as well as to the light - mode. In the dark - mode and at moderate humidity (set - point temperature $=40^{\circ} \mathrm{C}, \mathrm{Rh}=$ 40 - 60\%) leaf temperature (mean value $\pm S D, n=4$ ) of $R$. ferrugineum was $39.2^{\circ} \mathrm{C} \pm 0.2$. When $\mathrm{Rh}$ was $>95 \%$ leaf temperature was significantly $(\mathrm{P}<0.01)$ higher $\left(39.7^{\circ} \mathrm{C} \pm\right.$ 0.2 ). At the same time the difference between leaf temperature maximum and minimum decreased from $0.7 \mathrm{~K}$ to $0.3 \mathrm{~K}$ (according to Leuzinger et al. 2010 [30] temperatures are presented in ${ }^{\circ} \mathrm{C}$ and temperature differences in Kelvin (K) as is the custom in bioclimatology). In the light - mode the same procedure led to a significant $(\mathrm{P}<0.01)$ increase of leaf temperature from $39.7^{\circ} \mathrm{C} \pm 0.1$ to $39.9^{\circ} \mathrm{C} \pm 0.1$ and to a decrease between leaf temperature maximum and minimum from $0.8 \mathrm{~K}$ to $0.6 \mathrm{~K}$. While at moderate $\mathrm{Rh}$ leaf temperatures were substantially lower than the set - point temperature, heat exposure of leaves at high Rh (95 - 100\%) in any case led to a significant approximation of leaf temperatures to the target temperature with a simultaneous reduction of temperature scattering in terms of minima and maxima.

\section{Determination of heat tolerance: classical methods in comparison to the HTTS}

First experiments on alpine dwarf - shrubs demonstrate that both the heat exposure mode and the viability assay may have marked effects on the measured heat tolerance values. In the following results from three representative experiments are shown:

\section{Experiment (1) - V. gaultherioides}

To ensure comparability the exposure chambers of the HTTS were used in dark - mode and the viability was assessed by the visual estimation method (VEM) that was prior to the test calibrated and verified by comparison with a computer based digital determination of relative leaf injury (VAC) showing a high level of compliance $\left(45.8^{\circ} \mathrm{C} \pm 0.9\right.$ vs. $\left.45.9^{\circ} \mathrm{C} \pm 0.8\right)$ (Figure 2).

Leaf heat tolerance $\left(\mathrm{LT}_{50} \pm \mathrm{SD}\right)$ of $V$. gaultherioides when determined on detached leaves (ex situ) two days after a heat exposure that took place on 24 Jul 2012 in complete darkness using the exposure chambers from Buchner and Neuner (2001) [25] was $45.8^{\circ} \mathrm{C} \pm 0.9$. If - at the same time - the heat exposure was conducted in situ using the exposure chambers of the HTTS, heat tolerance was significantly $(\mathrm{P}<0.01)$ higher: $48.3^{\circ} \mathrm{C} \pm 0.8$. This also applies to heat tolerance values carried out on
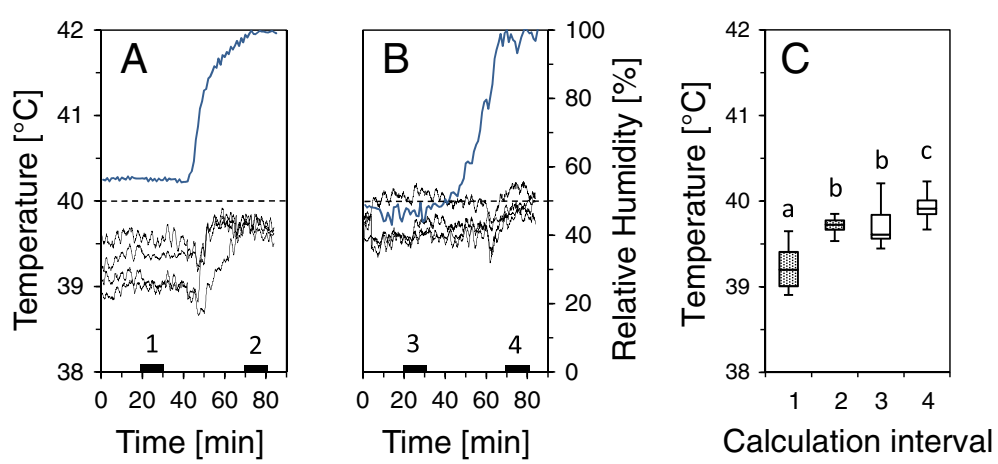

Figure 1 Effects of relative humidity on leaf temperature of $R$. ferrugineum inside of two heat exposure chambers. In the heat exposure chambers of the Heat Tolerance Testing System twigs were exposed to a sub - lethal air temperature $\left(+40^{\circ} \mathrm{C}\right)$ that was held constant $\mathbf{A}$. in darkness and $\mathbf{B}$. under full solar irradiation. Thin lines: leaf temperatures, bold lines: relative humidity, dashed lines: air temperature, solid rectangles: calculation periods for statistical comparisons. At high humidity (Rh $>90 \%$ ) leaf temperatures moved markedly closer to air temperature due to a strongly reduced transpiration. C. Box plots of the mean leaf temperature as a function of each calculation period. Boxes: median, upper and lower quartile. Whiskers: maximum, minimum. Dotted boxes: in darkness (data from A.), white boxes: at full sunlight (data from B.). At high humidity $(2,4)$ mean leaf temperatures had significantly $(P<0.01)$ increased due to the restricted leaf transpiration, while leaf temperature variability was clearly reduced. 


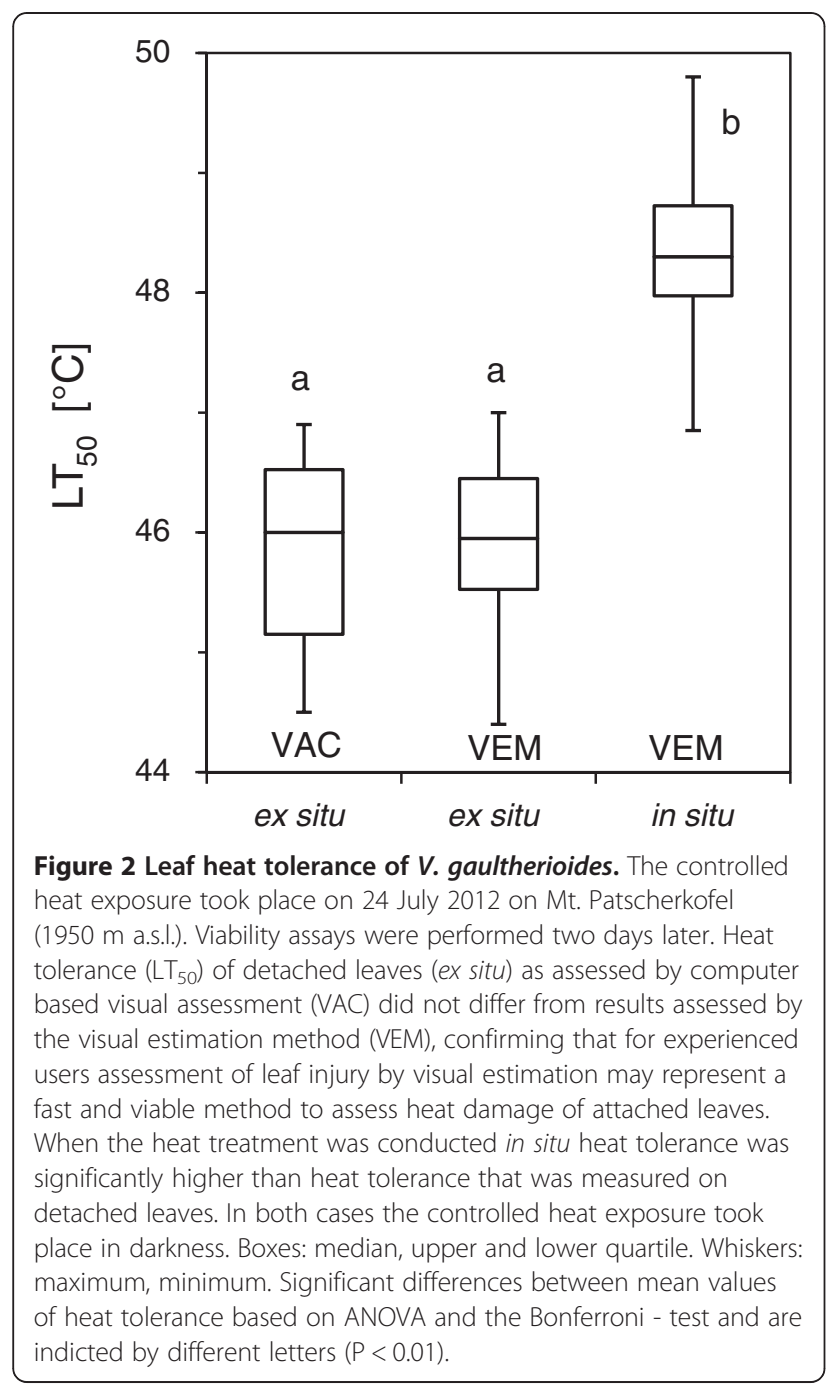

the same leaves but at a later time: $48.1^{\circ} \mathrm{C} \pm 1.0$ (28 Jul 2012), $48.5^{\circ} \mathrm{C} \pm 1.9$ (2 Aug 2012).

\section{Experiment (2) - L. procumbens}

Heat tolerance $\left(\mathrm{LT}_{50} \pm \mathrm{SD}\right)$ of detached leaves of L. procumbens (ex situ) as determined on 28 Sep 2011, two days after a controlled heat exposure, was $49.2^{\circ} \mathrm{C} \pm$ 1.2 if carried out by the electrolyte leakage test (ELT), and $48.4^{\circ} \mathrm{C} \pm 0.3$ if determined by VAC. The difference between the results from both assessment procedures was not significant $(P<0.05)$. In comparison to this heat tolerance was significantly $(\mathrm{P}<0.05)$ higher if determined in situ by the HTTS and VEM. This applies both for the heat exposure in the dark - mode $\left(50.6^{\circ} \mathrm{C} \pm 0.3\right)$ and in the light - mode $\left(53.3^{\circ} \mathrm{C} \pm 0.1\right)$. In other words: If heat exposure was conducted in darkness, $\mathrm{LT}_{50}$ as determined on detached leaves using ELT was significantly $(\mathrm{P}<0.05)$ lower by $2.2 \mathrm{~K}$ than $\mathrm{LT}_{50}$ as determined also in darkness but in situ. If heat exposure was conducted in situ and additionally under the presence of natural solar irradiation (light - mode) this difference was even higher $(4.9 \mathrm{~K})$. Heat tolerance of leaves that were exposed in light - mode was higher by $2.7 \mathrm{~K}$ than that of leaves that had to undergo the same procedure in the HTTS in darkness (Figure 3).

\section{Experiment (3) - R. ferrugineum}

Heat tolerance $\left(\mathrm{LT}_{50} \pm \mathrm{SD}\right)$ determined on leaves of $R$. ferrugineum by different heat exposure modes but identical viability assessment procedures led to significantly different results. Heat exposure took place on 27 Jul 2012. In the case of visual assessment (Figure 4A) three days after the heat exposure heat tolerance of detached leaves (ex situ, darkness, using the method of Buchner and Neuner 2001) [25] was $42.5^{\circ} \mathrm{C} \pm 0.5$ while it was significantly $(\mathrm{P}<0.05)$ higher $\left(44.5^{\circ} \mathrm{C} \pm 1.4\right)$ when

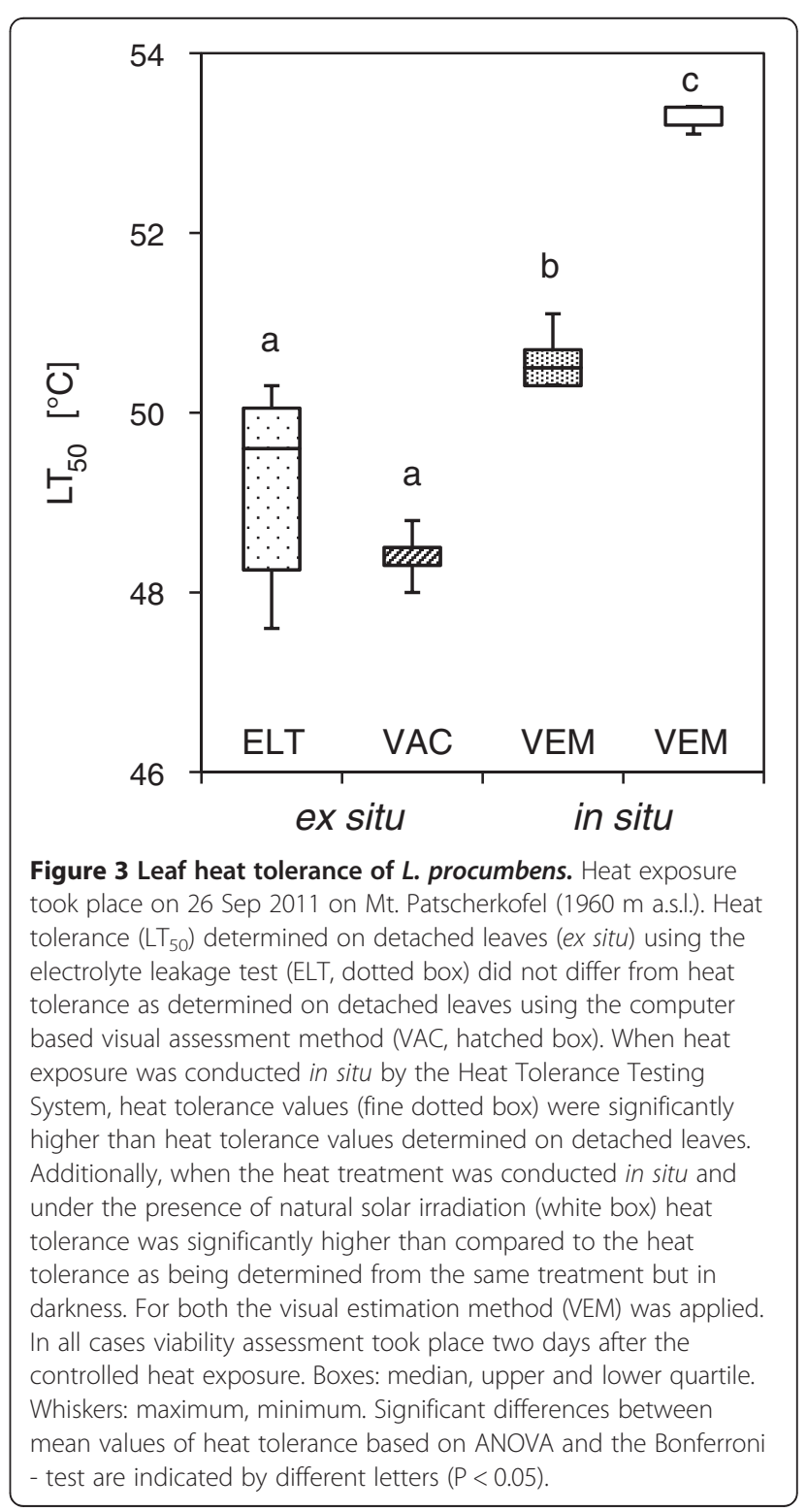



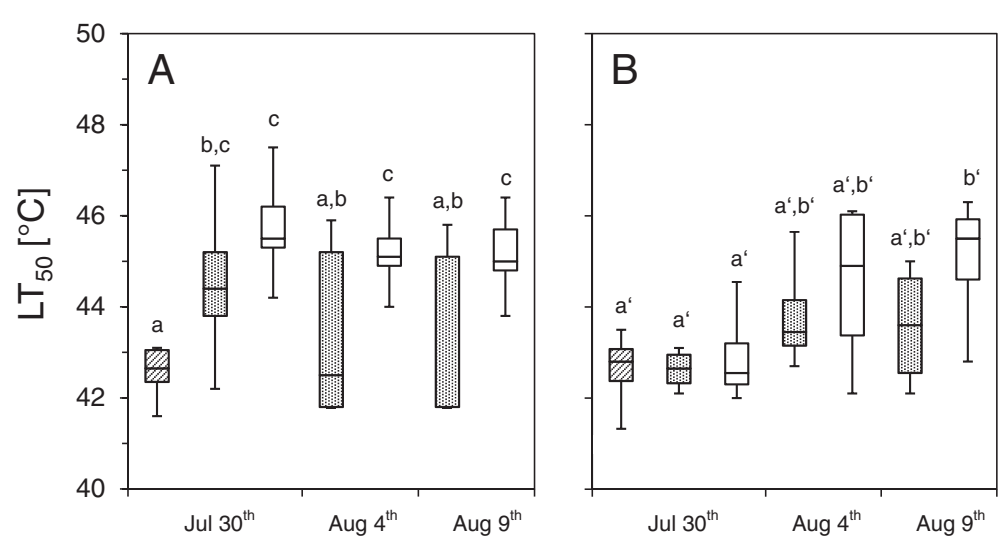

Figure 4 Leaf heat tolerance of $\boldsymbol{R}$. ferrugineum. Measurements were performed on Mt. Patscherkofel (1960 m a.s.l.) using different methodical approaches with regard to the controlled heat exposure. Measurements took place on 27 July 2012 and the following assessment procedures were used: 1. Heat exposure of detached leaves (ex situ, in darkness), 2. In situ heat exposure using the Heat Tolerance Testing System (in darkness and under natural solar irradiation). A. Viability assessed by the visual estimation method (VEM). LT 50 of excised leaves (hatched box) and $\mathrm{LT}_{50}$ determined in situ and in darkness (sprinkled box) did not differ significantly (exception: 30 July 2012). $\mathrm{LT}_{50}$ determined in situ under natural solar irradiation (white boxes) was always significantly higher. B. $\mathrm{LT}_{50}$ assessed by the chlorophyll fluorescence method (CHFL) showed no significant differences when detached leaves (hatched box) or attached leaves in situ in darkness (speckled box) were compared. $\mathrm{LT}_{50}$ determined in situ under natural solar irradiation (white boxes) was also not different except for 9 Aug 2012. Boxes: median, upper and lower quartile. Whiskers: maximum, minimum. Significant differences between mean values of heat tolerance based on ANOVA and the Duncan - test are indicated by different letters $(P<0.05)$.

heat exposure was performed in situ and in darkness using the HTTS. If leaves were simultaneously exposed to natural solar irradiation during heat exposure (in situ) heat tolerance was even higher $\left(45.8^{\circ} \mathrm{C} \pm 1.0 ; \mathrm{P}<0.05\right)$. This applies also to the results obtained in viability assessments taken some days later: $\mathrm{LT}_{50}$ based on in situ heat exposure in darkness: $43.5^{\circ} \mathrm{C} \pm 1.8$ (4 Aug 2012) and $43.1^{\circ} \mathrm{C} \pm 1.8$ (9 Aug 2012) was always significantly $(\mathrm{P}<0.05)$ lower than $\mathrm{LT}_{50}$ based on in situ exposure under natural solar irradiation: $45.3^{\circ} \mathrm{C} \pm 1.0$ (4 Aug 2012) and $45.2^{\circ} \mathrm{C} \pm 0.8$ (9 Aug 2012).

If viability assessment was done by chlorophyll fluorescence measurements $(\mathrm{Fv} / \mathrm{Fm})$ the differences between $\mathrm{LT}_{50}$ values were not as clear. However, apart from the first assessment date (30 Jul 2012) the trend was similar with the addition that in the case of dark - mode $\mathrm{LT}_{50}$ of detached leaves $\left(42.6^{\circ} \mathrm{C} \pm 0.8\right)$ and $\mathrm{LT}_{50}$ determined in situ $\left(42.6^{\circ} \mathrm{C} \pm 0.5 ; 30 \mathrm{Jul} 2012,43.9^{\circ} \mathrm{C} \pm 1.4 ; 4\right.$ Aug 2012 and $43.6^{\circ} \mathrm{C} \pm 1.4 ; 9$ Aug 2012$)$ were not significantly different $(\mathrm{P}<0.05)$. Leaf heat tolerance based on heat exposure under natural solar irradiation (in situ, mean PPFD $=650 \mu \mathrm{Mol}$ photons $\left.\cdot \mathrm{m}^{-2} \cdot \mathrm{s}^{-1}\right)$ was slightly higher $\left(43.0^{\circ} \mathrm{C} \pm 1.3 ; 30\right.$ Jul 2012), $\left(44.5^{\circ} \mathrm{C} \pm 1.9 ; 4\right.$ Aug 2012$)$ and $\left(45.0^{\circ} \mathrm{C} \pm 1.6 ; 9\right.$ Aug 2012) with the restriction that only the last result (9 Aug 2012) showed a significant $(\mathrm{P}<0.05)$ difference. The chlorophyll fluorescence method underestimated heat tolerance if the time span between heat exposure and viability assessment was not sufficiently long. It took eight recuperation days (4 Aug 2012) till $\mathrm{LT}_{50}$ values assessed by both methods had converged (Figure 4B).

\section{Discussion}

Although a lot of literature concerning the determination of stress tolerance of plants such as heat, frost and drought is available e.g. [10,11,13,18,20-22,24,25,31-34] a complete and detailed comparison of different methods especially for determining heat tolerance of plants is still missing. As both the heat exposure mode and the method of the following viability assessment have the potential to influence the outcome, results from one and the same sample may differ significantly. We have to state that there is not only one single method that could be appropriate under all circumstances. It depends on the scientific research question and the practical feasibility which method will be preferred. For the majority of scientific questions e.g. in the fields of plant breeding, genetic engineering and crop science appropriate and well established methods may exist. This is, however, not the case for ecological issues, where heat tolerance is understood as the potential to survive heat stress on the organ - or the whole plant - level under natural conditions. Primarily, for these special purposes the HTTS has been designed. The results from the present study underline the importance of conducting heat tolerance tests in situ and shall increase the experimenter's sensitivity for that issue.

\section{Effects of relative humidity on leaf temperature during heat exposure}

When relative humidity of the air inside the exposure chambers was increased to between 95 and 100\%, the difference between air and mean leaf temperature got 
clearly reduced. This is because of the physical laws governing leaf transpiration rate [35]. If the heat exposure chambers were operated in the dark - mode, individual leaf temperatures usually were lower than or equal to air temperature. Leaf transpiration and transpirational cooling gets quenched within a water saturated atmosphere when leaf and air temperature are the same. As transpiration rate and transpiration cooling usually is different for each individual leaf, also the differences within leaf temperatures are greater in non - saturated atmosphere than under water saturation.

\section{Effects of solar irradiation on leaf temperature}

In light - mode transpirational cooling is superimposed by the thermal load of absorbed solar irradiation depending on irradiation intensity, individual leaf angle, leaf orientation and shading. This is why leaf temperature may exceed air temperature despite transpirational cooling. A water vapour saturated atmosphere may additionally promote overheating and therefore, convective cooling inside the exposure chamber is particularly important. Furthermore, particularly at high altitudes the impact of solar irradiation on leaf temperature can be changed immediately due to fast passing clouds. The effects of rapidly altering solar irradiation on leaf temperature places great demands on the control unit of the HTTS that needs to combine a short response time with minimal overshooting to prevent deviation of leaf temperatures from target temperature. In the case of extremely adverse environmental conditions the accuracy of the system can be improved significantly by mounting thermocouple sensors on a couple of leaves and by setting the set - point temperature to the resulting mean leaf temperature that is continuously determined by the control software.

\section{Effects of detachment on leaf heat tolerance}

If leaves were detached (ex situ) this had significant effects on the determined heat tolerance value. $\mathrm{LT}_{50}$ of leaves from $V$. gaultherioides that had been detached before they were subjected to the controlled heat exposure was lower by $-2.5 \mathrm{~K}$ in comparison to leaves that were exposed without detachment (see Figure 2). This applied also to $L$. procumbens where this difference was $-2.2 \mathrm{~K}$. Further for detached leaves the results from ELT corresponded well with the results from VAC (see Figure 3). Also for $R$. ferrugineum a significant difference in heat tolerance $(-2.0 \mathrm{~K})$ due to leaf detachment was detectable three days after the heat exposure (see Figure 4A).

One reason for the mainly negative effect of detachment on heat tolerance may be that recuperation and repair processes at the cellular and molecular level can run more successfully if leaves remain attached to the plant, while in the case of detachment leaves are exposed mainly to degrading processes that may amplify the pattern of heat damage. Principally, countervailing effects are also conceivable, especially if the environmental conditions subsequent to the in situ heat exposure and during recovery are unfavourable for recuperation (e.g. environmental stresses such as drought, frost or excessive solar irradiation). Detached leaves are commonly exposed to standard laboratory conditions with high humidity, moderate, constant temperature and irradiation intensity that largely deviate from the natural situation. Hence, the de facto heat tolerance of a certain plant at a certain location will be better reflected by measurements that are conducted in situ than under artificial laboratory conditions using detached leaves.

\section{Effects of irradiation mode during heat exposure on heat tolerance}

Natural solar irradiation during in situ heat exposure increased leaf heat tolerance significantly in L. procumbens $(+2.7 \mathrm{~K})$ and in $R$. ferrugineum $(+1.3 \mathrm{~K})$ when compared to the results yielded after heat exposure in darkness. It could be demonstrated that solar irradiation may have a significant protective effect on heat stressed leaves. The reverse effect, a decline of heat tolerance due to the combined occurrence of heat and irradiation stress would principally also be conceivable, although our measurements do not give evidence for this.

Combined effects of irradiation and heat stress on leaf tissue are known for a long time [36-38] but the physiological mechanisms and constraints for possible protective effects of solar irradiation during heat stress are still widely unknown. As it is known that photosynthetic processes are more heat sensitive than the plasma membrane [39] in green tissue this effect possibly can be explained by photoinhibition which under certain conditions may act as a protective mechanism against heat stress [40].

However, our results demonstrate that the presence of natural solar irradiation during heat exposure is necessary for a realistic determination of heat tolerance of leaves in order to obtain results being ecologically more relevant.

Further in this experiment during the whole latent period heat tolerance based on the results of VEM (Figure 4A) differed distinctly from heat tolerance values obtained by the chlorophyll fluorescence method (CHFL) (Figure 4B). The reason for this may be that a reduction of Fv/Fm needs not to be linked exclusively to heat damage but also to a just temporary and reversible reduction of the maximum efficiency of photosystem II (PSII) - due to light, heat and other kind of stresses [23,41,42], which may considerably affect the calculation of lethal parameters such as $\mathrm{LT}_{50}$. Thus, CHFL, although it can be applied easily and in a non - invasive manner, cannot be recommended for determining heat tolerance without any 
restrictions, because it does not distinguish between photoinhibition and photodestruction. However, this shortcoming can be minimized by applying a sufficiently long recovery period between the heat exposure and the Fv/Fm measurements.

\section{Importance of the re - growth test}

Often it may be sufficient to determine heat tolerance $e x$ situ and based on detached plant parts or organs. Such methods have the advantage, that heat exposure can be conducted conveniently in the lab by avoiding natural weather conditions which often - especially at high altitudes - can be very challenging. However, if heat tolerance data with high ecological relevance are needed, heat stress must be applied under natural environmental conditions directly at the natural growing site of a plant. The advantage is that there is no need to detach the organs of interests. By this recuperation under fully natural conditions including external abiotic and biotic factors and their interactions can be studied. In frost experiments on conifers [31,32] it could be demonstrated that frost damage produced in winter took several weeks until frost damage had fully developed. If viability would have been assessed before the end of this extended latent period, frost hardiness would have been seriously overestimated. In the case of heat tolerance a similar influence of the time factor is conceivable although in summer environmental conditions, particularly temperature may be more favourable for a more rapid development of visible injuries. For example if viability is assessed by CHFL as shown for $R$. ferrugineum leaves, it can take several days (Figure 4B) or even weeks (data not shown) till PS II of heat stressed leaves is fully recovered which can have significant consequences on the calculated LT values. In that case the assessed heat tolerance value differed by $2 \mathrm{~K}$ depending on the timing of the measurement after heat exposure.

With respect to the considerable amount of heat tolerance data on arctic and alpine plants that is already available e.g. $[18,19]$ which have almost exclusively been derived from detached plant material, it can be expected that future results which will be obtained with the HTTS may significantly deviate from the existing data. Alpine vegetation is particularly prone to global climate change [4] because in alpine environments, abiotic factors, especially climate, dominate biotic interactions [43]. Changes in plant growth and reproduction [7] and upward shifts of vegetation belts are natural consequences and can already now be observed $[44,45]$. High mountain vegetation is at risk of drastic area losses, extinction and of disintegration of the current vegetation patterns which impacts the stability of high mountain ecosystems [4]. Especially for many pioneer plants the effects of the temperature increase may be severe [6]. Taking into account these facts, prediction models concerning alpine plant species in a global warming world will become increasingly important. Heat tolerance data determined by the HTTS may contribute to their accuracy and will sensitively affect their outcome.

\section{Conclusions}

This work does not claim to be a comparative study of all kinds of known viability assays that are currently in use, because there is not only one ideal method that can be applied to all cases. However, being aware that viability assessment can be very difficult and resultant tolerance levels can deviate to a large extent, various methods were employed in this study. The most appropriate method concerning heat tolerance testing depends on the research question, plant species, plant organ and the level on which the heat tolerance shall be determined (cellular level, tissue level or whole plant level or with respect to certain functions such as photosynthesis, growth, fruit production or reproduction). Furthermore, the time dimension has to be considered: Is it sufficient to get a snapshot of actual heat tolerance or shall the effects of recuperation or time dependent changes of heat injuries are taken into account? Before a specific heat tolerance test assembly can be chosen, the experimenter in any case has to clarify these questions in advance before the experiments may start.

We presented a novel system for determining heat tolerance of plants in situ without the necessity of detachment of plant organs. It allows controlled heat exposure of plants optionally in darkness or under full natural solar irradiation. Heat exposure is conducted within a water saturated atmosphere to keep the cooling effect of leaf transpiration on individual leaf temperature minimal which ensures that the leaves have virtually the same temperature as the air in the exposure chamber. Heat tolerance exemplarily obtained for leaves of three different alpine dwarf shrubs was shown to be strongly dependent on the fact whether heat exposure was performed in situ or on detached leaves. Additionally, application of natural irradiation during heat exposure affected leaf heat tolerance significantly. Heat tolerance was highest when heat stress was applied in situ under the presence of natural solar irradiation. Incorporating damage amplification, recuperation and repair into the results, heat tolerance data determined by the HTTS are highly ecologically significant and will increase the accuracy of prediction models related to the future destiny of high alpine plants considerably.

\section{Methods}

\section{Heat tolerance testing system}

With the Heat Tolerance Testing System (HTTS) it is possible to determine heat tolerance of plants without the necessity of detachment. The controlled exposure to 
pre - defined temperatures for a unique time span can be performed in situ, directly at the natural growing site and under largely undisturbed natural conditions particularly with regard to solar irradiation. The system consists of a field portable supply unit, 8 exposure chambers, a netbook and external sensors for measuring leaf temperatures, relative humidity (Rh), ambient air temperature and photon flux density (PPFD). It is operated by special software providing a virtual front panel which contains all necessary control and display elements.

\section{Supply unit}

The supply unit (Figure 5A) is built - in into a robust enclosure (PELICASE 1550, Peli Products, Provenca, Barcelona, Spain). A reconfigurable control and monitoring system (cRIO 9073: $266 \mathrm{MHz}$ real time controller, NI 9264: 16 bit analog output modules, NI 9205: 16 bit analog input modules, NI 9477: 32 channel sinking digital output modules, NI 9213: 16 channel thermocouple modules; National Instruments Corporation, Austin, TX, USA) acts as a link between the software and the hardware components as relay units, sensors, fans, pumps and heating elements that shall be addressed. The processes are mainly switched and controlled either user - editable or automatically by special software based on the software platform Lab View 2010 (National Instruments Corporation, Austin, TX, USA) running on a Netbook that communicates with the system by a standard RJ 45 connector and a 10/100 Mbps Base - $\mathrm{T}$ Ethernet port. The software contains virtual switches, diagrams, input and output fields and virtual indicator elements. In the background of the graphical programming interface PID (proportional - integral derivate) control algorithms assure minimal control fluctuations of the temperatures inside the exposure chambers.
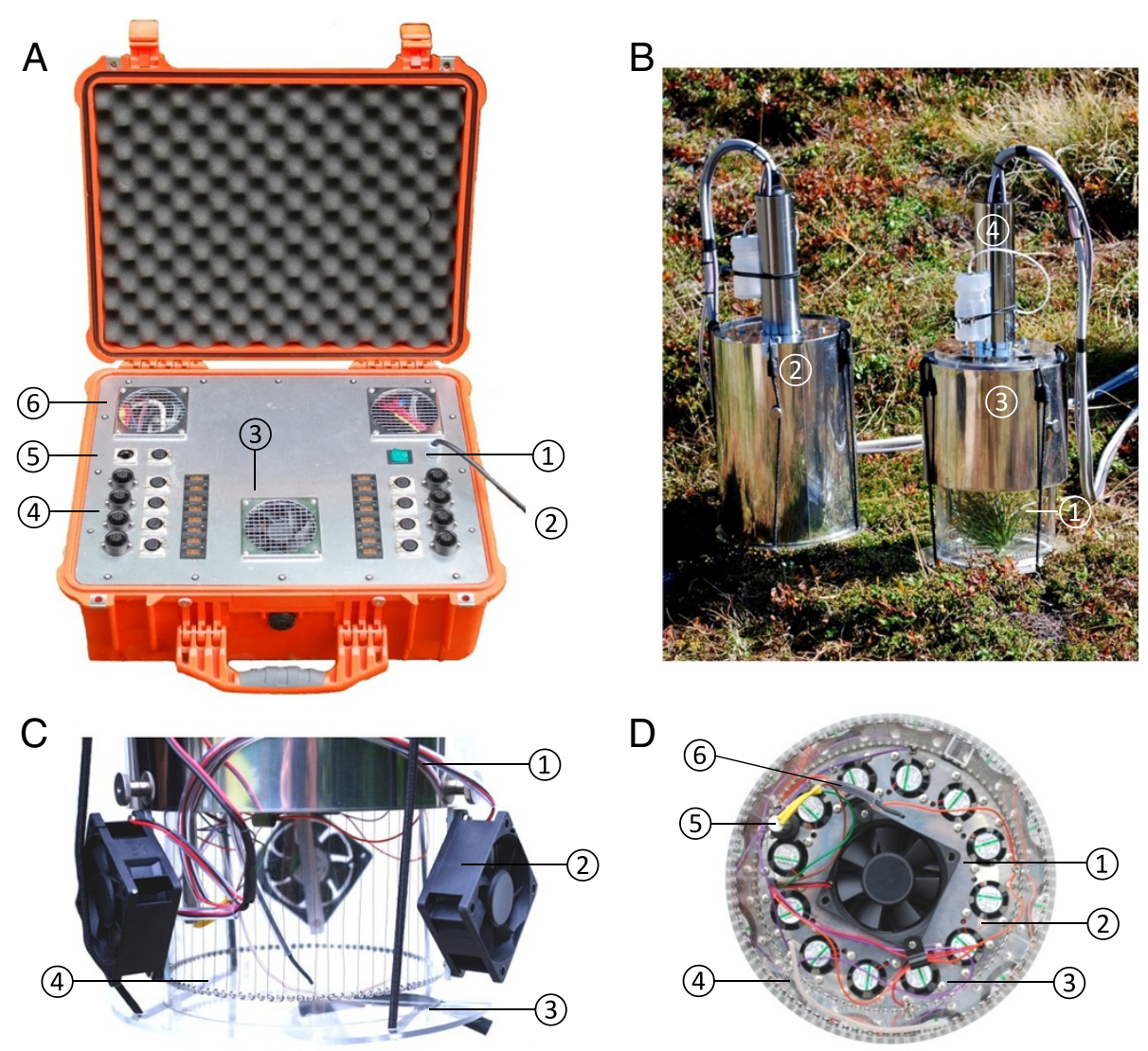

Figure 5 Major components of the heat tolerance testing system. A. The mobile supply unit is housed in a rugged and weather - proof enclosure. (1) Main switch, (2) power supply cable, (3) ventilation hole with fan, (4) connection panel for the eight exposure chambers, (5) RJ45 network port for connecting the notebook from which the complete system can be controlled, (6) venting hole (passive). B. Two exposure chambers in upright position during a controlled heat exposure. Heat exposure of a small Pinus cembra L. seedling (1) in dark - mode (2) and under natural solar irradiation (3). The handle (4) contains a hose pump and an electronic interface for controlling temperature and humidity inside the exposure chamber. $\mathbf{C}$. Side view of an exposure chamber. (1) Sunscreen, (2) external fan for cooling purposes, (3) transparent bottom with opening slit, (4) heating wires preventing condensation inside the chamber. $\mathbf{D}$. View into the inside of the heat exposure chamber. The main fan (1) transports air from the exposure room to the heating and humidifying system behind the separating plate (2) from where it is delivered back by 12 small fans (3). (4) Mobile temperature sensor, (5) humidity sensor (heated), (6) stationary temperature sensor. 


\section{Exposure chambers}

Each of the eight exposure chambers (Figure 5B-D) consists of a cylinder $(150 \times 250 \mathrm{~mm})$ made out of Plexiglas ${ }^{\circledR}$ (2 mm, Plexiglas ${ }^{\circledR}$ XT 29070, Röhm, Darmstadt, Germany). At one end the cylinder is open to insert the plant material, while the other side is closed by a Plexiglas ${ }^{\circledR}$ cover to which a handle is mounted. This handle is hollow and contains a miniature hose pump (RP-Q1, BMT Fluid Control Systems, Frankfurt, Germany) and further electronic components as fuses, relays, semiconductors and resistors. Across its length the Plexiglas ${ }^{\circledR}$ cylinder is divided into two different areas: (1) the exposure chamber in the strict sense and (2) the heat and humidity generating compartment which contains the central heating and humidifying element. Both compartments are separated by a frame of stainless steel containing one central fan blowing air from (1) to (2) and 12 concentrically arranged fans which transport the heated and humidified air into the opposite direction. To minimize temperature gradients inside the exposure chamber these fans can be operated either continuously or in an automatically switch on switch off mode of two crosswise arranged groups of six fans. The exposure chamber has two thermocouple sensors (Type T, solder junction diameter $<0.2 \mathrm{~mm}$, TT-TI-40, Omega Engineering Inc., Stamford, US) to record the actual temperature inside the chamber; one is installed in a fixed position while the other is highly flexible and can be mounted directly on the sample surface or another area of interest (Figure 5 D). Four additional thermocouples (same size) per exposure chamber are available for being mounted on leaves or other areas of interest. These thermocouples are equipped with special leaf clamps (Figure 6) consisting of a small PVC - strip and two miniature ring magnets (R09.3x06x01.05Ni-42H, Moeller, Flensburg, Germany). With these leaf clamps thermocouple sensors can be attached permanently and in a secure manner to a variety of different leaves without injuring them and without hindering leaf transpiration. Automatic temperature control can work based on one of the two thermocouples inside each exposure chamber (Figure 5D) or on actual mean leaf temperature at an update interval of one second.

The relative humidity inside the exposure chamber is measured by a combined humidity - temperature sensor (DKRF400-10-5000, Driesen und Kern, Bad Bramstedt, Germany). The inside of the exposure chamber is covered with heating filaments (Diameter: $0.2 \mathrm{~mm}, \mathrm{RD}$ 100/02, Isabellenhütte Heusler, Dillenburg, Germany) to avoid fogging that could influence spectral transmission of the Plexiglas ${ }^{\circledR}$.

The exposure chamber can be closed by a circular bottom plate of Plexiglas ${ }^{\circledR}$ which is fixed by rubber - belts. For inserting the plant samples this bottom plate has a slot that can be sealed with special cellular - rubber

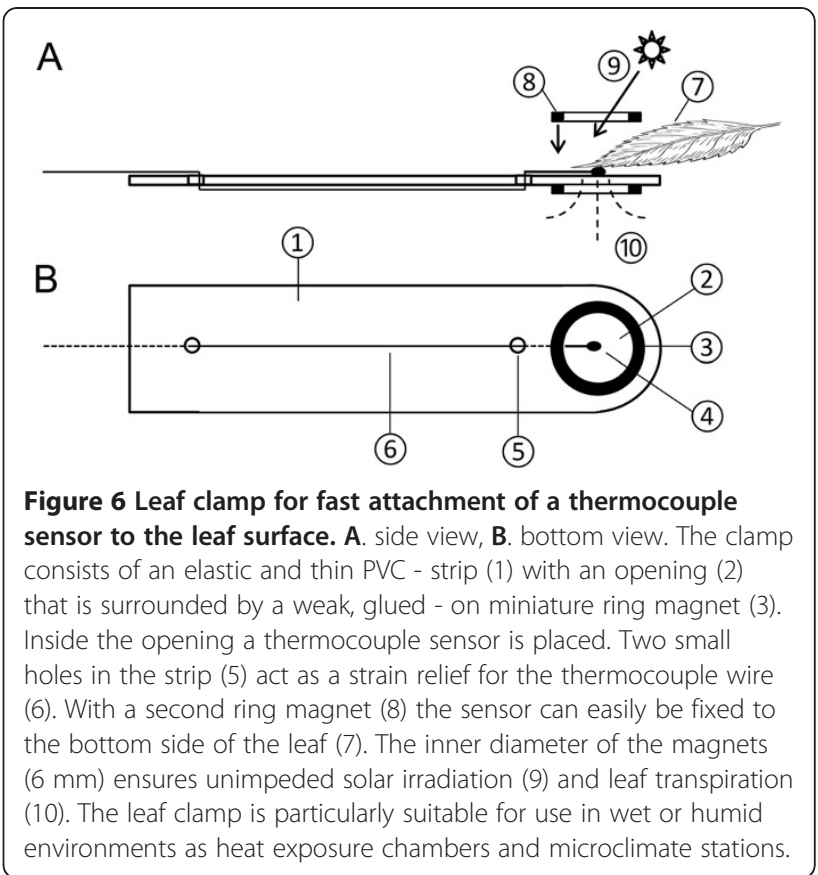

strips. To avoid uncontrolled overheating of the exposure chambers due to solar irradiation the upper part of the Plexiglas $^{\circledR}$ - cylinder is completely shielded by a sheet plate tube out of stainless steel (thickness: $0.2 \mathrm{~mm}$ ) that is mounted in a distance of $10 \mathrm{~mm}$ to the Plexiglas ${ }^{\circledR}$ - cylinder. Additionally three small fans can be mounted outside the chamber (Figure 5C). For complete darkening, special sheet - plate tubes are available that cover the whole surface. The device can thus be operated either in a "dark mode" or in a "light - mode". In the latter case the highly transmissible Plexiglas ${ }^{\circledR}$ ensures that all physiological relevant wavelengths from the spectrum of the solar irradiation will be transmitted to the sample without significant weakening (Figure 7).

\section{Plant material and experimental site}

Experiments were performed on leaves of the dwarf shrubs Vaccinium gaultherioides Bigelow, Rhododendron ferrugineum L. and Loiseleuria procumbens L. (Desv.), growing on a north facing slope at the timberline of Mt. Patscherkofel (1960 m a.s.l., 47 $12^{\prime} \mathrm{N} / 11^{\circ} 27^{\prime} \mathrm{E}$, Innsbruck, Austria) in September 2011 and July and August 2012.

\section{Effect of relative humidity on leaf temperature}

Controlled exposure of plants to a series of defined setup temperatures, which is a prerequisite for determining heat tolerance, can be disturbed by uncontrollable leaf transpiration. A simple method to prevent transpiration is to conduct heat exposure in a vapor saturated atmosphere. For illustration of the effect of vapor saturation on leaf temperature, twigs of $R$. ferrugineum were continuously $(90 \mathrm{~min})$ heated inside two exposure 


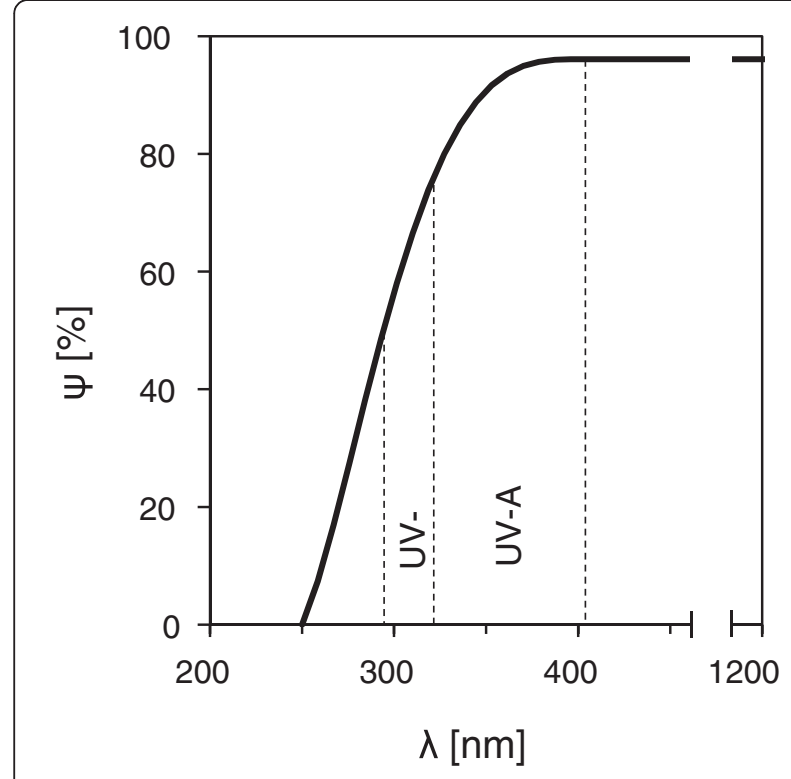

Figure 7 Spectral transmittance of Plexiglas ${ }^{\circledR}$ XT Clear 20070. The material, an extruded acrylic (polymethyl methacrylate) was used for the heat exposure chambers. For visible and near infrared light $(1200 \mathrm{~nm}>\lambda>380 \mathrm{~nm})$ it is highly transparent $(\psi=95 \%)$. Even the physiological relevant spectral ranges of UV-A $(380 \mathrm{~nm}>\lambda>$ $315 \mathrm{~nm})$ and UV-B (315 $\mathrm{nm}>\lambda>280 \mathrm{~nm}$ ) are transmitted by $80 \%$ and $50 \%$, respectively. $\lambda$ wavelength, $\psi$ spectral transmission. Source: adapted from Röhm GmbH, Darmstadt, Germany.

chambers of the HTTS (chamber 1: light - mode, chamber 2: dark - mode, set - point temperature: $40^{\circ} \mathrm{C}$, relative humidity: ca. 50\%) while leaf temperatures were recorded. After $45 \mathrm{~min}$ in both chambers relative humidity was started to increase to up to $100 \%$ (45 $\mathrm{min}$ ). Now representative periods (duration: $10 \mathrm{~min}$ ) at unaffected and increased relative humidity were selected and leaf temperatures were analyzed and compared using statistical methods.

\section{Comparative determination of heat tolerance}

Determinations of leaf heat tolerance were performed on R. ferrugineum, V. gaultherioides and L. procumbens with the objective to find out possible differences between the results carried out by commonly used methods in comparison to the HTTS. The determination of heat tolerance was always divided into two sequential steps: (1) controlled heat treatment, (2) viability assessment and calculation of lethal parameters including statistics. A summary of the different experiments including dates and details to the methods being applied is given in Table 1.

\section{Controlled heat treatment}

For the controlled heat treatment three different methods were employed: (1) ex situ using temperature controlled water baths [21], (2) ex situ using the equipment described in Buchner and Neuner [25], (3) in situ using the HTTS. All these approaches have in common that leaves get exposed to a specific temperature that is held constant for a unique time span of $30 \mathrm{~min}$. These specific sample temperatures were arranged in steps of $2 \mathrm{~K}$ difference and in a way that the lowest temperature did not cause any heat damage $(0 \%)$ while the highest temperature killed the leaves (100\% damage). A brief description of the three methods is given in the following:

(1)Ex situ - using temperature controlled water baths Detached leaves (10 per sample) of $L$. procumbens were inserted into small plastic bags and these, in turn, were immersed into temperature controlled water baths (CC1, Huber, Offenburg, Germany) and remained there at the pre - heated target temperature for $30 \mathrm{~min}$. The target temperatures were $20^{\circ} \mathrm{C}$ (control), $44^{\circ} \mathrm{C}, 46^{\circ} \mathrm{C}, 48^{\circ} \mathrm{C}, 50^{\circ} \mathrm{C}, 52^{\circ} \mathrm{C}$, $54^{\circ} \mathrm{C}$ and $60^{\circ} \mathrm{C}$ (100\% damage). To prevent transpiration of leaves during heat exposure, air was drawn out of the bags. After the heat treatment the leaves were placed on wet filter paper inside plastic bags and were exposed to room temperature and moderate irradiation conditions till the viability assessment took place.

Table 1 Basic data concerning the comparative experiments focused on heat tolerance of alpine dwarf - shrubs

\begin{tabular}{|c|c|c|c|c|c|c|}
\hline \multirow[t]{2}{*}{ No. } & \multirow[t]{2}{*}{ Species } & \multicolumn{3}{|c|}{ Heat exposure } & \multicolumn{2}{|c|}{ Viability assay } \\
\hline & & Date & & & Date & Method \\
\hline \multirow[t]{2}{*}{1} & V. gaultherioides & $24 \mathrm{Jul} 2012$ & $\mathrm{D}$ & ex situ? & $26 \mathrm{Jul} 2012$ & VAC, VEM \\
\hline & & 24 Jul 2012 & D & in situ & 26, $28 \mathrm{Jul} / 2$ Aug 2012 & VAC, VEM \\
\hline \multirow[t]{2}{*}{2} & L. procumbens & 26 Sep 2011 & D & ex situ ${ }^{2}$ & 27, 28 Sep 2011 & ELT, VAC \\
\hline & & 26 Sep 2011 & $D, L$ & in situ & 28 Sep 2011 & VEM \\
\hline \multirow[t]{2}{*}{3} & R. ferrugineum & $27 \mathrm{Jul} 2012$ & D & ex situ? & $30 \mathrm{Jul} 2012$ & VAC, CHFL \\
\hline & & $27 \mathrm{Jul} 2012$ & $\mathrm{D}, \mathrm{L}$ & in situ & $30 \mathrm{Jul} / 4,9$ Aug 2012 & VEM, CHFL \\
\hline
\end{tabular}

Heat exposure: ex situ using detached leaves ${ }^{1}$ following Buchner and Neuner (2001), ${ }^{2}$ in water baths, in situ, using the Heat Tolerance Testing System HTTS. Heat exposure took place in dark - mode (D) or in light - mode (L). Viability assessment: visual assessment by computer based measurement (VAC) of leaf damage, by estimating leaf damage (VEM), by electrolyte leakage test (ELT) and by the chlorophyll fluorescence method (CHFL). 
(2)Ex situ - using the equipment following Buchner and Neuner (2001)

This method is a further development of (1) and it works basically similar to it. The difference is that detached leaves can be measured immediately after excision directly in the field avoiding transportation times to the lab. By this, alterations of actual heat tolerance during transportation can be effectively avoided. Leaves were fixed to heat stable transparencies with adhesive tape $\left(3 \mathrm{M}^{\mathrm{TM}}\right.$ Transpore $^{\text {TM }}$, 3M Österreich GmbH, Perchtoldsdorf, Austria) which were sprayed with water to prevent transpirational cooling and sandwiched between small heating plates that are housed in a transportable suit case. This method was applied to $V$. gaultherioides and $R$. ferrugineum. In both cases target temperatures were set to $20^{\circ} \mathrm{C}$ (control), $38^{\circ} \mathrm{C}, 40^{\circ} \mathrm{C}, 42^{\circ} \mathrm{C}, 44^{\circ} \mathrm{C}, 46^{\circ} \mathrm{C}, 48^{\circ} \mathrm{C}, 50^{\circ} \mathrm{C}, 52^{\circ} \mathrm{C}$ and $60^{\circ} \mathrm{C}(100 \%$ damage).

(3) In situ - using the Heat Tolerance Testing System HTTS

Heat exposure took place within the exposure chambers of the HTTS either in darkness (dark - mode) or under natural solar irradiation (light - mode) in a water saturated atmosphere to eliminate transpiration. Target temperatures ranged from $45^{\circ} \mathrm{C}$ to $51^{\circ} \mathrm{C}$ ( V. gaultherioides, $R$.

ferrugineum) and from $44^{\circ} \mathrm{C}$ to $54^{\circ} \mathrm{C}$ (L. procumbens) and were arranged in steps of $2 \mathrm{~K}$ to cover the whole range $(0 \%$ to $100 \%)$ of damages induced by the heat treatment. The leaves could remain on the plant for the whole measurement procedure and also afterwards during the latent period before viability assessment. Viability assessment could be performed repeatedly, allowing for the inclusion of possible after effects like recuperation and stress induced acceleration of leaf senescence. With this method during the application of heat stress and in the whole latent period plants remained exposed under the natural environmental conditions.

\section{Viability assay}

The viability of the heat treated samples was assessed by the following frequently used methods: (1) electrolyte leakage test (ELT), (2) chlorophyll fluorescence measurements (CHFL) and (3) visual assessment of leaf injury by computer based measurements (VAC) or by the visual estimation method (VEM). The common thread to all these methods was that percentage leaf injury due to a certain stress temperature to which samples had been exposed was assessed after a latent period of two to three days (or more). The resulting dose - to - effect relationship (percentage damage vs. exposure temperature) followed a classical logistic function to which the data could be easily fitted. $\mathrm{LT}_{50}$, the standard lethal parameter indicating the temperature that caused $50 \%$ damage, was calculated automatically (Fig. - P 2.7, Biosoft, Durham, USA). The calculation of percentage damage $X_{T}$ [\%] was based on various temperature sensitive parameters $(P)$ using the following formula (1), where $P_{T}$ is the value of $P$ of a sample that had been exposed to a certain temperature $T, P_{O \%}$ is the value of $P$ of an uninjured sample that had been exposed to a harmless temperature $(\mathrm{T}=$ $20^{\circ} \mathrm{C}$ ) and $P_{100 \%}$ is the value of $P$ of a completely injured sample that had been exposed to a lethal temperature $\left(\mathrm{T}=60^{\circ} \mathrm{C}\right)$.

$$
X_{T}[\%]=100 \cdot \frac{P_{T}-P_{0 \%}}{P_{100 \%}-P_{0 \%}}
$$

\section{(1) Electrolyte leakage test (ELT)}

Principle: The ELT is a widely used and in numerous variants existing method based on the fact that heat stress affects cell membrane stability and semi - permeability causing a temperature dependent leaking of ions and solutes into the ambient solution that can be measured by an increase of electrical conductivity [20,46-49].

Experimental protocol: For L. procumbens subsequently to the controlled heat exposure leaves were cut

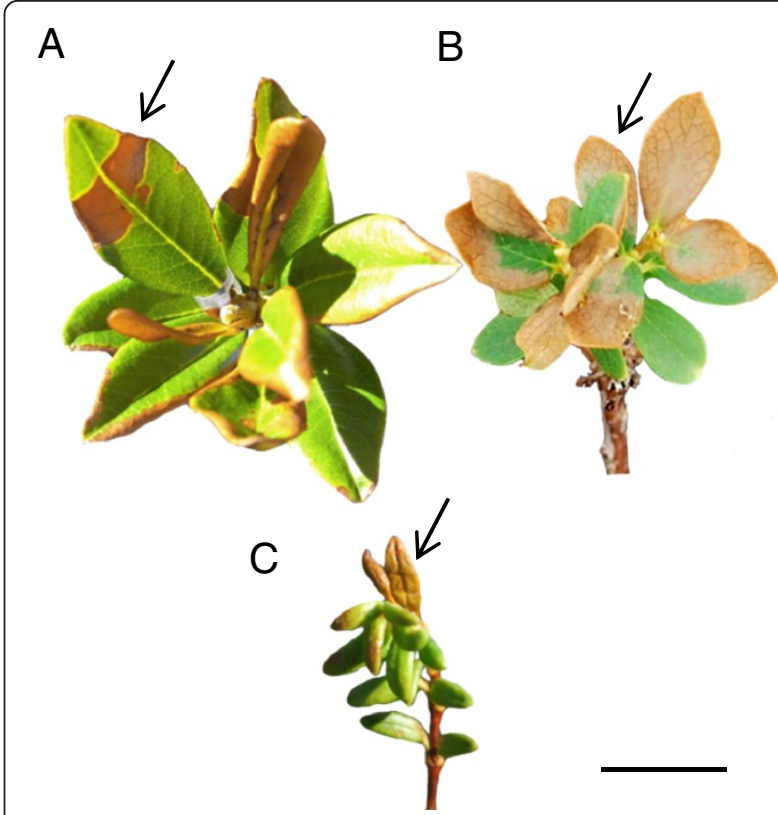

Figure 8 Heat induced injuries in leaves of three alpine dwarf shrubs. A. R. ferrugineum, B. V. gaultherioides and C. L. procumbens. Heat treatment was performed in situ with the Heat Tolerance Testing System under full natural solar irradiation during summer 2012 on Mt. Patscherkofel (1960 m a.s.l.). As in these species damaged leaf areas show typical, sharped - edged discolorations (arrows) the proportion of damaged to intact leaf area per leaf can easily be determined. Black line: $1 \mathrm{~cm}$. 
in a right angle into four individual pieces and transferred into small vials (six parallels, twelve pieces per vial) which were filled with $3 \mathrm{ml}$ of distilled water and $800 \mu \mathrm{g} \mathrm{l}^{-1}$ of dissolved gentamicin, an aminoglycoside antibiotic, to prevent microbial contamination. Subsequently these samples were infiltrated by application of a vacuum with a vacuum pump (LKC 251 E, Saskia, Ilmenau, Germany) to remove air from the intercellular spaces in the mesophyll which otherwise would have hindered the leakage of ions into the solution. After $24 \mathrm{~h}$ the specific electrical conductivity $(G)$ of the leachates was determined with a conductivity meter (HD 9213, Delta Ohm, Hungen, Germany). After setting $G=P, X_{\mathrm{T}} \%$ was calculated for each sample using formula (1).

\section{(2) Chlorophyll fluorescence (CHFL)}

Principle: Chlorophyll fluorescence parameters are particularly sensitive to heat stress [34,50-55]. A possible criterion for the assessment of injuries on the primary photosynthetic apparatus is $\mathrm{F}_{\mathrm{v}} / \mathrm{F}_{\mathrm{m}}$, a stress sensitive fluorescence parameter describing the maximum photochemical efficiency of Photosystem II (PS II). The stress related reduction of $\mathrm{F}_{\mathrm{v}} / \mathrm{F}_{\mathrm{m}}$ can be used as a simple tool for the assessment of leaf damage [22,33].

Experimental protocol: We determined $\mathrm{F}_{\mathrm{v}} / \mathrm{F}_{\mathrm{m}}$ on ten dark adapted leaves (30 $\mathrm{min}$ ) before and after heat treatment (PEA MK2, Hansatech Instruments Ltd, Norfolk, $\mathrm{UK})$. As a result of heat stress $\mathrm{F}_{\mathrm{v}} / \mathrm{F}_{\mathrm{m}}$ was reduced, depending on the exposure temperature. In this protocol again, $\mathrm{X}_{\mathrm{T} \%}$ was calculated for each sample by setting $\mathrm{F}_{\mathrm{v}} / \mathrm{F}_{\mathrm{m}}=-\mathrm{P}$ and using formula (1).

\section{(3) Visual assessment (VAC, VEM)}

Principle: Due to cell membrane damage and loss of cell integrity heat stress induced injuries become apparent as discolorations on damaged leaf areas, especially if cell content is rich on phenolic compounds as e.g. in leaf tissue of many Ericaceae (Figure 8). Visual assessment methods have proved highly effective wherever leaf injuries can be detected as visible color changes [13,25,56].

Experimental protocol: For the visual assessment of heat injuries the relative proportion of damaged leaf area per leaf was determined ( $V$. gaulterhioides: 32 leaves, L. procumbens and R. ferrugineum: 10 leaves). This happened by surveying leaf areas (injured areas divided to total leaf area) of scanned leaves using special graphical analyzing software (Optimas 6.5, Optimas Corp., Seattle, USA) (VAC) or by visual estimation (VEM) of percentage leaf area that was damaged. For leaves VAC normally is the method of choice. As it is not generally applicable to leaves still attached to the plant, for in situ measurements it was replaced by the visual estimation method (VEM) that produced similar results. The results from the visual assessment methods (VAC, VEM) were ratios between 0 and 1, which were set into formula (1) to calculate percentage damage $\mathrm{X}_{\mathrm{T}}[\%]$.

\section{Statistics}

For descriptive statistical data analysis and comparisons of mean values SPSS - software (SPSS Version 18.0, SPSS Inc., Chicago, US) was used. Mean values were compared either by Student's $\mathrm{t}$ - test or by analysis of variance (ANOVA) followed by post hoc tests as the Bonferroni test or the Duncan - test.

\section{Competing interests}

The authors declare that they have no competing interests.

\section{Authors' contributions}

$\mathrm{OB}$ initiated the project, designed and built the HTTS and the control software; $\mathrm{OB}$ and MK carried out the experiments and analysed the data; IB designed and constructed the magnetic leaf clamps for temperature measurement within the exposure chambers. OB wrote the manuscript, GN contributed to the manuscript and provided additional input. All authors read and approved the final manuscript.

\section{Funding}

This work was enabled by the Austrian Science Fund (FWF - project 22158 B16 to O. Buchner).

Received: 3 December 2012 Accepted: 7 March 2013

Published: 14 March 2013

\section{References}

1. Körner C: Alpine plant life. Functional plant ecology of high mountain ecosystems. Berlin: Springer; 1999.

2. Körner C, Larcher W: Plant life in cold climates. In Plants and temperature. Edited by Long S, Woodward Fl. Cambridge: Comp. Biol. Ltd; 1988:25-57.

3. Beniston M, Diaz HF, Bradley RS: Climate change at high elevation sites: an overview. Climate Change 1997, 36:233-251.

4. Pauli H, Gottfried M, Grabherr G: Effects of climate change on the alpine and nival vegetation on the Alps. J Mt Ecol 2003, 7:9-12.

5. Erschbamer B: Responses of some Austrian glacier foreland plants to experimentally changed microclimate condition. In "Fingerprints" of climate change. Edited by Walther GR, Burga CA, Edward PJ. New York: Kluwer Academic/Plenum Pubishers; 2001:263-280.

6. Erschbamer B: Winners and losers of climate change in a central alpine glacier foreland. Arct Antarct Alp Res 2007, 39:237-244.

7. Kudernatsch T, Fischer A, Bernhardt-Römermann M, Abs C: Short-term effects of temperature enhancement on growth and reproduction of alpine grassland species. Basic Appl Ecol 2008, 9:263-274.

8. IPCC Intergovernmental Panel on Climate Change: Climate Change 2007. The Physical Science Basis. In Contribution of Working Groups I to the Fourth Assessment Report of the Intergovernmental Panel on Climate Change. Edited by Solomon S, Qin D, Manning M, Chen Z, Marquis M, Averyt KB, Tignor M, Miller HL. United Kingdom, New York: Cambridge University Press; 2007.

9. Ciais P, Reichstein M, Viovy N, Granier A, Oge J, Allard V, Aubinet M, Buchmann N, Bernhofer C, Carrara A, Chevallier F, De Noblet N, Friend AD, Friedlingstein $P$, Grünwald T, Heinesch B, Keronen P, Knohl A, Krinner G, Loustau D, Manca G, Matteucci G, Miglietta F, Ourcival JM, Papale D, Pilegaard K, Rambal S, Seufert G, Soussana JF, Sanz MJ, Schulze ED, Vesala T, Valentini R: Europe-wide reduction in primary productivity caused by the heat and drought in 2003. Nature 2005, 437:529-533.

10. Wahid A, Gelani S, Ashraf M, Foolad M: Heat tolerance in plants: an overview. Environ Exp Bot 2007, 61(3):199-223.

11. Alexandrov VY: Cells, molecules and temperature. In Ecological Studies vol. 21. Berlin: Springer; 1977.

12. Neuner $G$, Buchner $O$, Braun $V$ : Short-term changes in heat tolerance in the alpine cushion plant Silene acaulis ssp. excapa (All.) J. Braun at different altitudes. Plant Biology 2000, 2:677-683.

13. Buchner $\mathrm{O}$, Neuner $\mathrm{G}$ : Variability of heat tolerance in alpine plant species measured at different altitudes. Arct Antarct Alpine Res 2003, 35:411-420. 
14. Lange OL: Die Hitzeresistenz einheimischer immer- und wintergrüner Pflanzen im Jahreslauf. Planta 1961, 56:666-683.

15. Larcher W, Kainmüller C, Wagner J: Survival types of high mountain plants under extreme temperatures. Flora 2010, 205(1):3-18.

16. Kjelvik S: Varmeresistens og varmeveksling for noen planter, vesentlig fra Hardangervidda. Blyttia 1976, 34:211-226.

17. Larcher W, Wagner J: Temperaturgrenzen der CO2-Aufnahme und der Temperaturresistenz der Blätter von Gebirgspflanzen im vegetationsaktiven Zustand. Oecologia Plantarum 1976, 11:361-374.

18. Gauslaa Y: Heat resistance and energy budget in different Scandinavian plants. Holarctic Ecol 1984, 7:1-78.

19. Neuner G, Buchner O: Dynamics of tissue heat tolerance and thermotolerance of PS II in alpine plants. In Plants in Alpine Regions. Edited by Lütz C. Berlin: Springer; 2012:61-74.

20. Sullivan CY: Mechanism of heat and drought resistance in grain sorghum and methods of measurement. In Sorghum in the Seventies. Edited by Rao NGP, House LR. New Delhi, India: Oxford and IBH Publ. Co; 1972:247-264.

21. Kreeb KH: Hitzeresistenz. In Methoden zur Pflanzenökologie und Bioindikation. Edited by Kreeb KH. Jena: Gustav Fischer; 1990:72-75.

22. Jiang $H$, Howell GS: Using chlorophyll fluorescence (Fv/Fm) as an objective, sensitive, and efficient method to determine cane tissue hardiness of grapevines. Hort Sci 1998, 33(3):510.

23. Willits $\mathrm{DH}$, Peet MM: Measurement of chlorophyll fluorescence as a heat stress indicator in tomato: laboratory and greenhouse comparisons. J Amer Soc Hort Sci 2001, 126(2):188-194.

24. Kreeb KH, Nachuzrischwili KMG: Zur ökologischen Resistenz von Hochgebirgspflanzen des Zentralkaukasus in Abhängigkeit von der Höhenstufe. In Sitzungsbericht der Österreichischen Akademie der Wissenschaften, mathematisch - naturwissenschaftliche Klasse. Vienna: Austrian Academy of Sciences; 1990:81-110.

25. Buchner $O$, Neuner $G$ : Determination of heat tolerance: a new equipment for field measurements. J App/ Bot 2001, 75:130-137.

26. Cottee N, Bange M, Tan D, Campbell L, Cothren JT: Multi-level determination of heat tolerance in cotton (Gossypium hirsutum L.) under field conditions. Crop Sci 2010, 50(6):2553-2564.

27. Mishra S, Heckathorn SA, Barua D, Wang D, Joshi P, Hamilton EW III, Frantz J: Interactive effects of elevated $\mathrm{CO}_{2}$ and ozone on leaf thermotolerance in field-grown glycine max. J Integr Plant Biol 2008, 50(11):1396-1405.

28. Ristic Z, Bukovnik U, Momcilović I, Fu J, Vara Prasad PV: Heat-induced accumulation of chloroplast protein synthesis elongation factor, EF-Tu, in winter wheat. J Plant Physiol 2008, 65(2):192-202.

29. Cordukes WE: Growth habit and heat tolerance of a collection of Poa annua plants in Canada. Can J Plant Sci 1977, 57(4):1201-1203.

30. Leuzinger $S$, Vogt $R$, Körner C: Tree surface temperature in an urban environment. Agr Forest Meteorol 2010, 150:56-62.

31. Buchner $\mathrm{O}$, Neuner $\mathrm{G}$ : A low temperature freezing system to study the effects of freezing temperatures to $-70^{\circ} \mathrm{C}$ on trees in situ. Tree Physiol 2009, 29:313-320.

32. Buchner $\mathrm{O}$, Neuner $\mathrm{G}$ : Winter frost resistance of Pinus cembra measured in situ at the alpine timberline as affected by temperature conditions. Tree Physiol 2011, 31(11):1217-1227.

33. Neuner G, Buchner O: Assessment of foliar frost damage: a comparison of in vivo chlorophyll fluorescence with other viability tests. J Appl Bot 1999, 73:50-54.

34. Bilger HW, Schreiber U, Lange OL: Determination of leaf heat resistance: comparative investigation of chlorophyll fluorescence changes and tissue necrosis methods. Oecologia 1984, 63:256-262.

35. Willert DJ, Matyssek R, Herppich W: Experimentelle Pflanzenökologie. Stuttgart: Thieme; 1995

36. Ludlow MM: Light stress at high temperature. In Photoinhibition. Edited by Kyle DG, Osmond CB, Arnitzen CJ. Amsterdam: Elsevier; 1987:89-109.

37. Havaux M, Greppin H, Strasser RJ: Functioning of Photosystem I and Photosystem II in pea leaves exposed to heat - stress in the presence or absence of light: analysis using in - vivo fluorescence, absorbency, oxygen and photoacoustic measurements. Planta 1991, 186:88-98.

38. Yamada $\mathrm{M}$, Hidaka $\mathrm{T}$, Fukamachi $\mathrm{H}$ : Heat tolerance in leaves of tropical fruit crops as measured by chlorophyll fluorescence. Sci Hort 1996, 67(1-2):39-48.

39. Berry J, Bjorkman O: Photosynthetic response and adaptation to temperature in higher plants. Ann Rev Plant Phys 1980, 31:491-543

40. Havaux M: Stress tolerance of photosystem II in vivo. Plant Physiol 1992, 100:424-432.
41. Valladares F, Pearcy RW: Interactions between water stress, sun-shade acclimation, heat tolerance and photoinhibition in the sclerophyll Heteromeles arbutifolia. Plant Cell Environ 1997, 20:25-36.

42. Osmond CB: What is photoinhibition? Some insights from comparisons of shade and sun plants. In Photoinhibition of photosynthesis, from molecular mechanisms to the field. Edited by Baker NR, Bowyer JR. Oxford, United Kingdom: Bios Scientific Publishers; 1994:1-24

43. Cannone N, Sgorbati S, Guglielmin M: Unexpected impacts of climate change on alpine vegetation. Front Ecol Environ 2007, 5(7):360-364.

44. Grabherr G, Gottfried M, Pauli H: Climate effects on mountain plants. Nature 1994, 369:448.

45. Walther GR, Beißner S, Burga CA: Trends in the upward shift of alpine plants. J Veg Sci 2005, 16:541-548.

46. Dexter ST, Tootingham WE, Graber LF: Investigations of the hardiness of plants by measurement of electrical conductivity. Plant Physio/ 1932, 7:63-78.

47. Gavuzzi P, Rizza F, Palumbo M, Campanile RG, Ricciardi GL, Borghi B: Evaluation of field and laboratory predictors of drought and heat tolerance in winter cereals. Can J Plant Sci 1997, 77(4):523-531.

48. Ruter JM: Foliar heat tolerance of two hybrid hollies. Hort Sci 1993, 28(6):650-652

49. Levitt J: Responses of Plants to Environmental Stresses: Chilling, freezing, and high temperature stresses. New York: Academic Press; 1980.

50. Schreiber $U$, Berry JA: Heat-induced changes of chlorophyll fluorescence in intact leaves correlated with damage of the photosynthetic apparatus. Planta 1977, 136:233-238.

51. Weis E, Berry JA: Plants and high temperature stress. In Plants and Temperature. Edited by Long SP, Woodward FI. Cambridge: Comp. Biol. Ltd; 1988:329-346.

52. Larcher W, Wagner J, Lütz C: The effect of heat on photosynthesis, dark respiration and cellular ultrastructure of the arctic-alpine psychrophyte Ranunculus glacialis. Photosynthetica 1997, 34:219-232.

53. Weng JH, Lai MF: Estimating heat tolerance among plant species by two chlorophyll fluorescence parameters. Photosynthetica 2005, 43:439-444.

54. Neuner G, Pramsohler M: Freezing and high temperature thresholds of photosystem II compared to ice nucleation, frost and heat damage in evergreen subalpine plants. Physiol Plantarum 2006, 126:196-204.

55. Dongsansuk A, Lütz C, Neuner G: Effects of temperature and irradiance on quantum yield of PSII photochemistry and xanthophyll cycle in a tropical and a temperate species. Photosynthetica 2013, 51(1):13-21.

56. Neuner $G$, Larcher $W$, Bannister P: Ice formation and foliar frost resistance in attached and excised shoots from seedlings and adult trees of Nothofagus menziesii. New Zeal J Bot 1997, 35:221-227.

doi:10.1186/1746-4811-9-7

Cite this article as: Buchner et al:: A novel system for in situ determination of heat tolerance of plants: first results on alpine dwarf shrubs. Plant Methods 2013 9:7.

\section{Submit your next manuscript to BioMed Central and take full advantage of:}

- Convenient online submission

- Thorough peer review

- No space constraints or color figure charges

- Immediate publication on acceptance

- Inclusion in PubMed, CAS, Scopus and Google Scholar

- Research which is freely available for redistribution 